\title{
Extracellular Signal-Regulated Protein Kinase Activation Is Required for Metabotropic Glutamate Receptor-Dependent Long-Term Depression in Hippocampal Area CA1
}

\author{
Sean M. Gallagher, ${ }^{1}$ Christine A. Daly, ${ }^{1}$ Mark F. Bear, ${ }^{2}$ and Kimberly M. Huber ${ }^{1}$ \\ ${ }^{1}$ Center for Basic Neuroscience, Department of Physiology, University of Texas Southwestern Medical Center, Dallas, Texas 75390, and ${ }^{2}$ Howard Hughes \\ Medical Institute and The Picower Center for Learning and Memory, Massachusetts Institute of Technology, Cambridge, Massachusetts 02139
}

Activation of group 1 metabotropic glutamate receptors (mGluRs) induces long-term depression (LTD) of synaptic transmission that relies on dendritic protein synthesis. We investigated the signal transduction pathways required for mGluR-LTD to identify candidate mechanisms for mGluR regulation of synaptic protein synthesis. Our results demonstrate a role for extracellular signal-regulated protein kinase (ERK), a subclass of the mitogen-activated protein kinases (MAPKs), in mGluR-LTD in area CA1 of the rat hippocampus. Inhibitors of the upstream kinase of ERK, MAP/ERK kinase significantly reduce mGluR-LTD induced by the group 1 agonist dihydroxyphenylglycine (DHPG) and synaptic stimulation but do not affect NMDA receptor-dependent LTD. In contrast, inhibitors of p38 MAPK were ineffective against DHPG-induced LTD. Consistent with the role of ERK in mGluR-LTD, we observed that DHPG treatment of hippocampal slices (isolated CA1), at concentrations that induce LTD, results in a robust phosphorylation of ERK but not of p38 MAPK. These results point to ERK as an important regulator of mGluR-LTD and a potential mechanism for mGluR regulation of synaptic protein synthesis.

Key words: metabotropic glutamate receptor; long-term depression; ERK; hippocampus; CA1; p38 MAPK

\section{Introduction}

Activation of group 1 metabotropic glutamate receptors (mGluRs) induces long-lasting changes in neuronal and synaptic function that rely on new protein synthesis but are independent of transcription (Merlin et al., 1998; Huber et al., 2000; Raymond et al., 2000; Snyder et al., 2001). These findings suggest that mGluRs can directly regulate mRNA translation in neurons, but how this occurs is unknown.

One consequence of mGluR activation, either with the selective agonist dihydroxyphenylglycine (DHPG) or with synaptic stimulation [paired-pulse low-frequency stimulation (PP-LFS)], is long-term depression (LTD) of synaptic transmission of excitatory synapses on hippocampal CA1 pyramidal neurons (mGluR-LTD) (Palmer et al., 1997; Fitzjohn et al., 1998; Kemp and Bashir, 1999). Stable expression of mGluR-LTD requires rapid, dendritic mRNA translation without new transcription (Huber et al., 2000; Zho et al., 2002). There is evidence that mGluR-LTD reflects a lasting reduction of postsynaptic glutamate receptor expression (Snyder et al., 2001; Xiao et al., 2001) and presynaptic glutamate release (Fitzjohn et al., 2001; Watabe

Received Sept. 30, 2003; revised March 17, 2004; accepted April 13, 2004.

This research was supported in part by the National Institutes of Health, Howard Hughes Medical Institute (M.F.B.), and McKnight and FRAXA Research Foundations (K.M.H.). K.M.H. is a Southwestern Medical Foundation endowed scholar in biomedical research. We thank Gray Pearson and Melanie Cobb for helpful discussions and technical assistance with the Western blots.

Correspondence should be addressed to Kimberly Huber, Center for Basic Neuroscience, University of Texas Southwestern Medical Center, 5323 Harry Hines Boulevard, Dallas, TX75390-9111. E-mail: Kimberly.Huber@UTSouthwestern.edu. DOI:10.1523/JNEUROSCI.5407-03.2004

Copyright $\odot 2004$ Society for Neuroscience $\quad$ 0270-6474/04/244859-06\$15.00/0 et al., 2002; Zakharenko et al., 2002; Rammes et al., 2003). Both postsynaptic and presynaptic changes are blocked by protein synthesis inhibitors (Snyder et al., 2001; Zakharenko et al., 2002). Therefore, mGluR-LTD provides a powerful model to understand how group $1 \mathrm{mGluRs}$ regulate protein synthesis-dependent synaptic plasticity.

Because group $1 \mathrm{mGluRs}$ activate the phospholipase $\mathrm{C}$ cascade, it is surprising that protein kinase $\mathrm{C}$ inhibitors, depletion of intracellular $\mathrm{Ca}^{2+}$ stores, or postsynaptic $\mathrm{Ca}^{2+}$ chelators do not affect DHPG-induced LTD (DHPG-LTD) (Schnabel et al., 1999; Fitzjohn et al., 2001). Instead, there is a report that tyrosine phosphatase inhibitors block DHPG-LTD (Moult et al., 2002). Group 1 mGluRs activate other signal transduction cascades, such as the mitogen-activated protein kinases (MAPKs) (Peavy and Conn, 1998; Ferraguti et al., 1999; Roberson et al., 1999; Bolshakov et al., 2000; Karim et al., 2001; Peavy et al., 2001). Of the MAPKs, mGluRs have been shown to activate two subclasses, the extracellular signal-regulated protein kinase (ERK) and p38 MAPK. ERK has been implicated in mGluR-LTD in the cerebellum (Ahn et al., 1999; Kawasaki et al., 1999) and DHPG-induced increases in excitability in CA3 neurons (Zhao et al., 2004). Interestingly, both of these responses to mGluR activation are also dependent on protein synthesis (Merlin et al., 1998; Karachot et al., 2001). However, inhibitors of p38 MAPK block LTD induced by synaptic stimulation of mGluRs in neonatal [postnatal day 4 (P4)-P10] area CA1 (Bolshakov et al., 2000), as well as LTD induced by DHPG in the dentate gyrus of juvenile (3- to 4-week-old) rats (Rush et al., 2002). In hippocampal slice culture, p38 MAPK 
inhibitors also block NMDA receptor (NMDAR)-dependent LTD (NMDAR-LTD) (Zhu et al., 2002). Therefore, current evidence suggests that p38 MAPK may be a common signaling mechanism that leads to LTD.

Here we investigated the signal transduction pathways specifically required for protein synthesis-dependent LTD induced by DHPG and PP-LFS in area CA1 of juvenile rats. Surprisingly, our experiments reveal a role for ERK rather than p38 MAPK in this form of LTD. These results demonstrate a role for ERK in group 1 mGluR-mediated synaptic depression and implicate the ERK pathway as a candidate mechanism for the regulation of synaptic protein synthesis by mGluRs.

\section{Materials and Methods}

Hippocampal slice preparation and electrophysiology. Hippocampal slices were prepared as described previously (Huber et al., 2000) from LongEvans rats (P21-P30; Charles River, Cambridge, MA). Slices were collected in ice-cold dissection buffer containing (in mM) 212 sucrose, 2.6 $\mathrm{KCl}, 1.25 \mathrm{NaH}_{2} \mathrm{PO}_{4}, 26 \mathrm{NaHCO}_{3}, 5 \mathrm{MgCl}_{2}, 0.5 \mathrm{CaCl}_{2}$, and 10 dextrose. $\mathrm{CA} 3$ was cut away from each slice immediately after sectioning. Slices were allowed to recover for $2-5 \mathrm{hr}$ at room temperature or $30^{\circ} \mathrm{C}$ in artificial CSF (ACSF) containing (in $\mathrm{mm}$ ): $124 \mathrm{NaCl}, 5 \mathrm{KCl}, 1.25$ $\mathrm{NaH}_{2} \mathrm{PO}_{4}, 26 \mathrm{NaHCO}_{3}, 1 \mathrm{MgCl}_{2}, 2 \mathrm{CaCl}_{2}$, and 10 dextrose. ACSF and dissection buffer were saturated in $95 \% \mathrm{O}_{2}$ and $5 \% \mathrm{CO}_{2}$. For recording, slices were placed in a submersion recording chamber, maintained at $30^{\circ} \mathrm{C}$, and perfused with ACSF at a rate of $2-2.5 \mathrm{ml} / \mathrm{min}$. Field potentials (FPs) were acquired in area CA1 and the dentate gyrus as described previously (Huber et al., 2000; Rush et al., 2002). The group data were analyzed as described previously (Huber et al., 2000). Data plotted in all figures represent average \pm SEM. Significant differences between groups were determined using an independent or paired (see Fig. 2) $t$ test.

Drug preparation. $R, S$-DHPG, AP-5, 4-(4-fluorophenyl)-2-(4-hydroxyphenyl)-5-(4-pyridyl)1H-imidazole (SB202190), 4-(4-fluorophenyl)-2-(4methylsulfinylphenyl)-5-(4-pyridyl)imidazole (SB203580), 1,4-diamino-2, 3-dicyano-1,4-bis[2-amino-phenylthio]butadiene (U0126), ( $S$ )(+)- $\alpha$-amino-a-methylbenzeneacetic acid (LY367385), and 2-methyl-6(phenylethynyl)-pyridine (MPEP) were purchased from Tocris Cookson (Ballwin, MO). 1,4-Diamino-2,3-dicyano-1,4-bis(methylthio)butadiene (U0124) and 2-(2-diamino-3-methoxyphenyl-4H-1-benzopyran-4-one (PD98059) were purchased from Calbiochem (La Jolla, CA). All inhibitors were prepared as stocks in DMSO or $\mathrm{H}_{2} \mathrm{O}$ (LY367385 and MPEP), stored at $-20^{\circ} \mathrm{C}$, and freshly diluted to a final concentration in ACSF.

Immunoblotting for MAPKs. Slices (containing area CA1 and dentate gyrus; $\mathrm{CA} 3$ was cut off) were maintained in a static incubation chamber in ACSF at $30^{\circ} \mathrm{C}$ and aerated with $95 \% \mathrm{O}_{2}-5 \% \mathrm{CO}_{2}$. Immediately after DHPG treatment, slices were frozen and stored at $-80^{\circ} \mathrm{C}$. For ERK, slices were homogenized in lysis buffer containing 50 mM HEPES, pH 7.3, 150 mм NaCl, $1.5 \mathrm{~mm} \mathrm{MgCl}_{2}$, 1 mм EGTA, 10\% glycerol, $0.2 \mathrm{~mm} \mathrm{NaVO}_{4}, 100$ $\mathrm{mm} \mathrm{NaF}, 50$ mм $\beta$-glycerophosphate, $1 \mathrm{~mm}$ dithiothreitol, $1 \mathrm{~mm}$ benzamidine, $0.01 \mathrm{mg} / \mathrm{ml}$ leupeptin, $0.1 \mathrm{mg} / \mathrm{ml}$ aprotonin, $0.5 \mu \mathrm{g} / \mathrm{ml}$ pepstatin $\mathrm{A}$, and $1 \%$ Triton X-100. For $\mathrm{p} 90$ ribosomal protein S6 kinase (RSK) and p38 MAPK, $1.8 \%$ Triton X-100 was added. Samples containing 20-35 $\mu \mathrm{g}$ of protein were resolved on $10 \%$ SDS-PAGE and transferred to nitrocellulose. Membranes were blocked and incubated with the following antibodies according to the manufacturer's protocol: phosphospecific $(\mathrm{P})$ ERK (Thr202/Tyr204; 1:5000 dilution; Promega, Madison, WI), P-p38 MAPK (Thr180/Tyr182; 1:500), P-RSK1 (Thr359/Ser363; 1:1000), total ERK (1:1000), and total p38 MAPK (1:1000). All antibodies were from Cell Signaling Technologies (Beverly, MA), except for phospho-ERK. Blots were washed and incubated in HRP-conjugated secondary antibody (1:1500; MP Biomedical, Aurora, $\mathrm{OH}$ ). Bands were detected using enhanced chemiluminescence. Densitometric quantification of immunopositive bands was done using Scion Image (Scion Corporation, Frederick, MD). Only film exposures that were in the linear range of the ECL reaction were used for analysis.

\section{Results}

\section{ERK is required for mGluR-LTD in juvenile CA1}

A previous study demonstrated that group 1 mGluRs activate ERK in the hippocampus (Roberson et al., 1999). Therefore, we examined the requirement for ERK activation in DHPG-LTD. Extracellular FPs elicited by Schaffer collateral stimulation were recorded from area CA1 dendrites. After a stable baseline period, LTD was induced with a brief ( $5 \mathrm{~min}$ ) application of DHPG (50 or $100 \mu \mathrm{M})$. ERK1 and ERK2 are activated when phosphorylated by the dual-specificity kinase MAP/ERK kinase (MEK) (Pearson et al., 2001). Preincubation of hippocampal slices with U0126 (20 $\mu \mathrm{M})$, a selective and membrane-permeable MEK inhibitor, significantly inhibited the later phase of DHPG-LTD induced with either 50 or $100 \mu \mathrm{M}$ DHPG compared with interleaved vehicle (DMSO) controls (at 60-65 min after treatment: $50 \mu \mathrm{M}$ DHPG plus vehicle, $77 \pm 4 \%$ of pretreatment baseline, $n=6 ; 50 \mu \mathrm{M}$ DHPG plus U0126, $91 \pm 4 \%, n=6, p=0.01 ; 100 \mu \mathrm{M}$ DHPG plus vehicle, $83 \pm 2 \%, n=9 ; 100 \mu \mathrm{M}$ DHPG plus U0126, $95 \pm 5 \%$, $n=5, p=0.03$ ) (Fig. 1A). DHPG-LTD was also reduced by second MEK inhibitor, PD98059 (100 $\mu$ M DHPG plus vehicle, $73 \pm 4 \%, n=6 ; 100 \mu \mathrm{M}$ DHPG plus $50 \mu \mathrm{M}$ PD98059, $91 \pm 3 \%$, $n=4 ; p=0.01)$ (Fig. $1 B$ ). In contrast, preincubation with the inactive analog of U0126, U0124 (20 $\mu \mathrm{M})$ did not affect DHPGinduced LTD (U0124, $79 \pm 4 \%, n=7$; vehicle, $79 \pm 2 \%, n=4$; $p=0.95$ ).

We also tested the effects of U0126 on LTD induced with PP-LFS (pairs of stimuli at a $50 \mathrm{msec}$ interstimulus interval delivered at $1 \mathrm{~Hz}$ for $15 \mathrm{~min}$; 1800 pulses total) in the presence of the NMDA receptor antagonist DL-AP-5 $(100 \mu \mathrm{M})$. Like DHPGinduced LTD, the later phase of PP-LFS-induced LTD (55-60 min after PP-LFS) was significantly inhibited by U0126 (93 \pm $4 \% ; n=9)$ compared with vehicle controls $(79 \pm 3 \% ; n=9 ; p=$ $0.008)$.

Another form of LTD coexists at CA1 synapses and is dependent on NMDAR (NMDAR-LTD). Consistent with the idea that mGluR- and NMDAR-LTD are mediated by distinct cellular mechanisms (Oliet et al., 1997; Huber et al., 2000), U0126 did not affect NMDAR-LTD induced with LFS (Fig. 1D) (U0126, $73 \pm$ $4 \%, n=6$; vehicle, $70 \pm 7 \%, n=6$; $p=0.69$ ). These results indicate that ERK is specifically required for $\mathrm{mGluR}$-and protein synthesis-dependent LTD.

\section{p38 MAPK is not required for DHPG-induced LTD in area CA1}

In the dentate gyrus, the p38 MAPK inhibitor SB203580 (1 $\mu \mathrm{M})$ blocks DHPG-LTD (Rush et al., 2002). However, we found that neither $1 \mu \mathrm{M}$ SB203580 nor another p38 MAPK inhibitor (SB202190, $1 \mu \mathrm{M}$ ) had any significant effect on DHPG-LTD in CA1 (LTD with $1 \mu \mathrm{M}$ SB203580, $84 \pm 3 \%, n=8$; interleaved control LTD, $85 \pm 2 \%, n=8$; LTD with $1 \mu \mathrm{M} \mathrm{SB202190,} 88 \pm$ $2 \%, n=8$; interleaved control LTD, $88 \pm 3 \%, n=9$ ). To confirm these findings, we repeated the experiment using a longer preincubation $(\geq 1 \mathrm{hr})$ with a greater concentration (5 $\mu \mathrm{M})$ of SB203580. In addition, we simultaneously recorded the effects of $100 \mu \mathrm{M}$ DHPG (5 min) in the absence or presence of drug on FPs in the dentate gyrus and CA1 (Fig. 2). As reported previously, we observed that DHPG induced significant LTD in the dentate gyrus $(85 \pm 4 \% ; n=9$; paired $t$ test; $p=0.004$ ) (Fig. $2 A)$ that was blocked by SB203580 (99 $\pm 1 \% ; n=7 ; p=0.13)$ (Fig. 2B). Again, however, we observed robust DHPG-LTD in area CA1 in $5 \mu \mathrm{M}$ SB203580 ( $80 \pm 1 \% ; n=10$; paired $t$ test; $p=$ 0.0001 ) (Fig. $2 C$ ) that was similar to control slices (0.1\% DMSO, $78 \pm 4 \% ; n=7$ ) (Fig. 2D). 

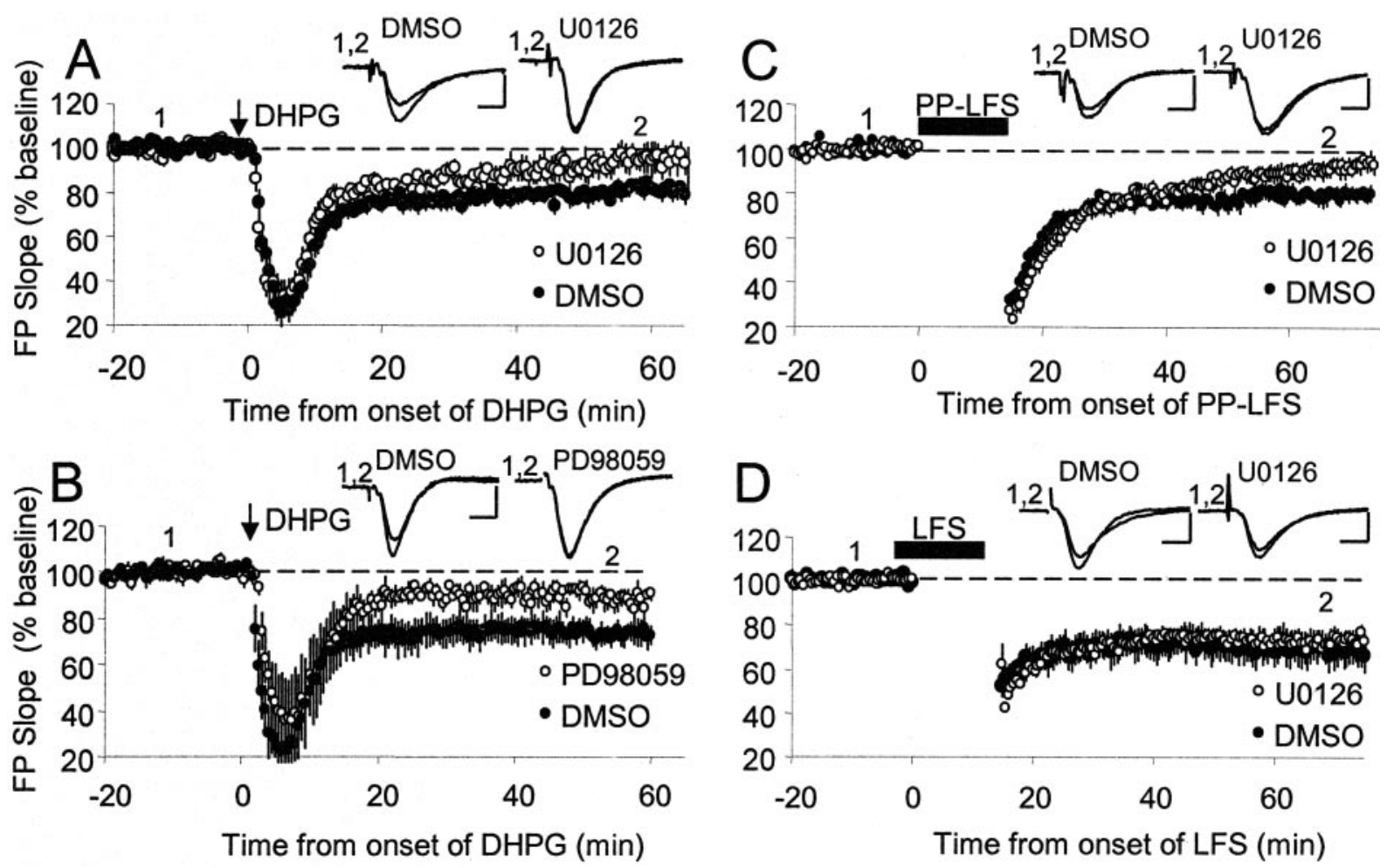

Figure 1. MEK inhibitors selectively inhibit mGluR-LTD. Preapplication of the MEK inhibitors U0126 (A, $20 \mu \mathrm{M})$ or PD98059 (B, $50 \mu \mathrm{M})$ reduced DHPG-LTD. In this and Figure 2, representative EPSP waveforms ( 2 min average) taken from an experiment at the times indicated by the numbers on the graph are shown. Calibration: $0.5 \mathrm{mV}, 5 \mathrm{msec}$. C, U0126 also inhibited LTD induced with PP-LFS [ 900 paired pulses ( 50 msec interpulse interval) delivered at $1 \mathrm{~Hz}$ ] in the presence of $100 \mu \mathrm{m} \mathrm{DL}-A$ P-5. D, U0126 (20 $\mu \mathrm{m})$ did not affect NMDA receptor-dependent LTD induced by LFS ( 900 pulses at $1 \mathrm{~Hz}$ ). Dashed lines indicate $100 \%$ of baseline.
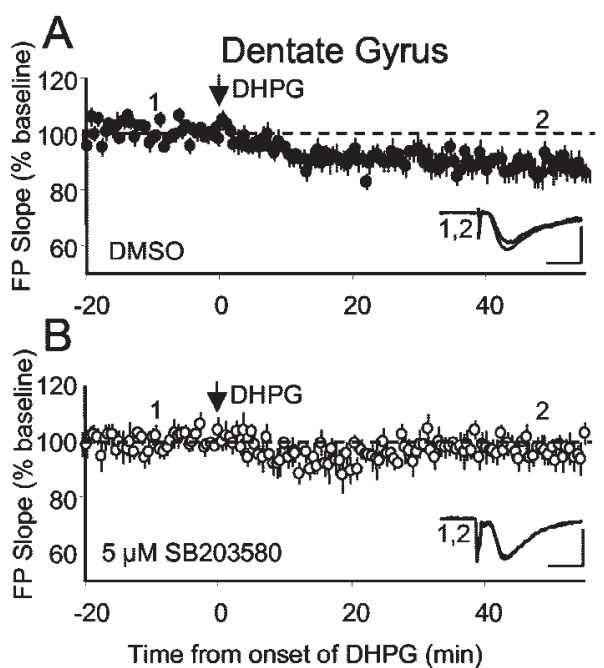

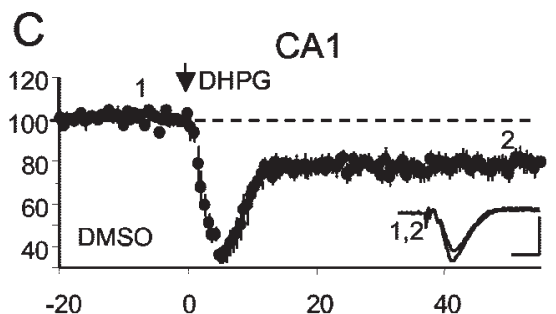

$D^{-20}$

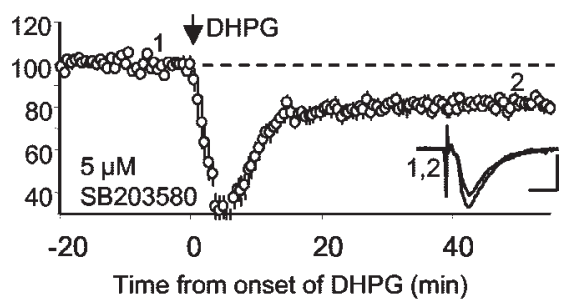

Figure 2. $\quad$ p38 MAPK is not required for DHPG-induced LTD in area CA1. A, B, Application of DHPG (100 $\mu \mathrm{m}, 5 \mathrm{~min}$, in $0.1 \%$ DMSO) to hippocampal slices induced LTD in FPs recorded in the dentate gyrus $(A)$ and area $C A 1(C) . B, D$, Preapplication of the $p 38$ MAPK inhibitor SB203580 (5 $\mu \mathrm{m}, 1 \mathrm{hr}$ ) prevents LTD in the dentate gyrus $(B)$ but does not affect LTD in area CA1 (D). Dashed lines indicate $100 \%$ of baseline.

DHPG induces phosphorylation of ERK but not p38 MAPK in juvenile CA1

To further confirm a role for ERK in LTD, we determined whether concentrations of DHPG that induce LTD also resulted in activation of ERK in hippocampal slices (isolated CA1), using antibodies that recognize the dually phosphorylated (Thr202/ Tyr204) and active ERK. We observed an increased phosphorylation of ERK (both ERK1 and ERK2 combined) with $100 \mu \mathrm{M}$
DHPG $(273 \pm 26 \%$ of basal or ACSF treated slices; $n=7 ; p<0.0001$ ) (Fig. $3 A$ ) that persisted in the presence of tetrodotoxin (TTX) and AP-5 (50 $\mu \mathrm{M}$ DHPG, $205 \pm 24 \%, n=8 ; 100 \mu \mathrm{M}$ DHPG, $226 \pm$ $25 \%, n=8, p=0.21$, vs $100 \mu \mathrm{M}$ DHPG in ACSF). This indicates that DHPGinduced ERK activation was not an indirect consequence of increasing slice excitability or activating NMDARs. In contrast, the combined application of the mGluR1 and mGluR5 antagonists [LY367385 (100 $\mu \mathrm{M})$ and MPEP $(10 \mu \mathrm{M})$ respectively] significantly reduced DHPG-induced ERK phosphorylation (125 $\pm 7 \%$ of basal levels; $n=6$; $p<0.0009$ ) compared with DHPG alone (470 $\pm 64 \%$; $n=6$ ) (Fig. $3 B$ ). As expected, preincubation of slices in the MEK inhibitor U0126 $(20 \mu \mathrm{M})$ reduced phosphorylated ERK levels to $51 \pm 18 \%$ of basal levels $(n=5)$ and completely blocked DHPGinduced increases in ERK phosphorylation $(59 \pm 12 \%$ of basal levels; $n=6$; $p=0.76$ compared with basal plus U0126) (Fig. 3A).

The ERK substrate RSK1 has been shown to translocate to polyribosomes with DHPG activation (Angenstein et al., 1998). Using phosphospecific antibodies to RSK1 (Thr359/Ser363), we have detected an increase in RSK phosphorylation in hippocampal slices in response to DHPG $(100 \mu \mathrm{M}, 5 \mathrm{~min}, 150 \pm 9 \%, n=15$ compared with control slices; $p<0.01$ ) (Fig. $3 B$ ) that is blocked 
by the MEK inhibitor U0126 (102 $\pm 11 \%$; $n=10 ; p<0.01$; compared with DHPG alone).

To determine whether DHPG induces phosphorylation of p38 MAPK, we performed Western blots on hippocampal slices with phosphospecific (Thr180/ Tyr182) antibodies to p38 MAPK. Unlike ERK, we were not able to detect significant increases in p38 MAPK phosphorylation after DHPG treatment $(100 \mu \mathrm{M}, 5 \mathrm{~min}$, $112 \pm 7 \% ; n=7 ; p=0.12$ ). Together, our results suggest that there are differences in the signal transduction mechanisms required for mGluR-LTD in the dentate gyrus and area CA1.

\section{Discussion}

Our data demonstrate a requirement for ERK in mGluR-LTD and suggest that ERK may also be an important signaling molecule for regulation of protein synthesis at synapses. Surprisingly, we did not find a role for p38 MAPK in DHPG-induced LTD. Consistent with the involvement of ERK in LTD, we observed a robust phosphorylation of ERK and RSK in response to DHPG at concentrations that induce LTD in hippocampal brain slices. These findings demonstrate a functional role for ERK in mGluR-dependent synaptic depression in the hippocampus and provide candidate signaling pathways for mGluR regulation of synaptic protein synthesis.

\section{Role of ERK in mGluR-dependent synaptic plasticity}

It has been demonstrated previously that the group $1 \mathrm{mGluR}$ agonist DHPG activates ERK in hippocampal slices (Roberson et al., 1999). However, a role for ERK in mGluR-mediated physiological changes has only been described recently (Coogan et al., 1999). Here, we have shown a selective effect of MEK inhibitors on LTD induced with DHPG and synaptic stimulation. In contrast, NMDAR-dependent LTD induced with LFS is unaffected (Fig. 1). Consistent with our finding, a recent study in slice culture found that the MEK inhibitor PD98059 did not interfere with NMDAR-dependent LTD (Zhu et al., 2002). Because DHPG-induced and PP-LFS-induced LTD are both dependent on dendritic protein synthesis, as opposed to NMDARdependent LTD, these results suggest that ERK may be important in regulating synaptic protein synthesis. However, the effects of the MEK inhibitors were not as rapid or robust as the effects of protein synthesis inhibitors, especially in the case of PP-LFS (Huber et al., 2000). The incomplete blockade of mGluR-LTD by U0126 is not attributable to an incomplete blockade of ERK activation (Fig. 3A). Therefore, this suggests that other signaling pathways may play an earlier or additional role in mGluR-LTD.

There is previous evidence for ERK in hippocampal LTD in vivo. A previous study in area CA1 in vivo found that systemic administration of the MEK inhibitor $\alpha$-[amino[(4-aminophenyl) thio]methylene]-2-(trifluoromethyl)benzeneacetonitrile (SL327) inhibits LTD (Thiels et al., 2002). Although the induction of LTD is this study required NMDARs (Thiels et al., 1994; Heynen et al.,
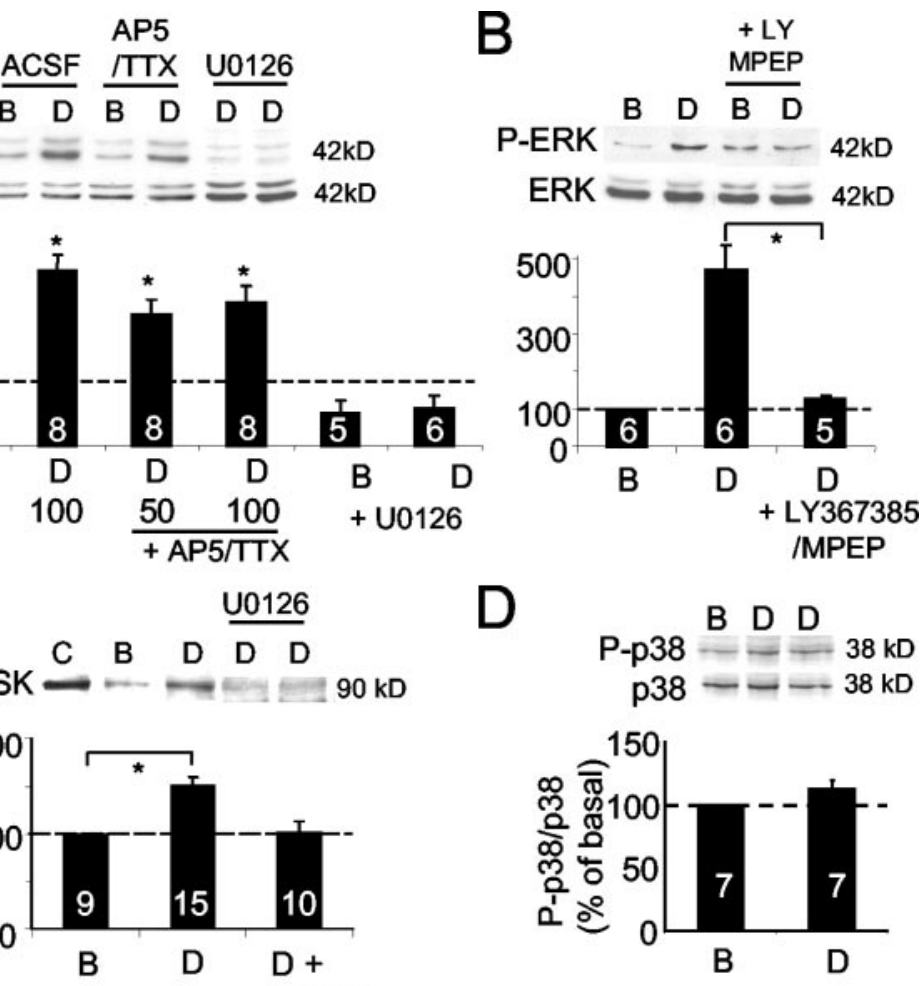
inhibit mGluR-LTD in adolescent CA1. Consistent with these data, DHPG does not activate p38 MAPK in area CA1. Our slices contained dentate gyrus, so it is surprising that we were not able to detect p38 MAPK activation the slices. However, this could be caused by a signal-to-noise problem, and a comparison of DHPG-stimulated p38 MAPK in the dentate gyrus versus CA1 subregions may be required. Our data suggest that p38 MAPK may be differentially required for LTD depending on the brain region.

\section{Role for ERK in long-term potentiation and LTD?}

Our data demonstrating a role for ERK in mGluR-dependent LTD add to the growing body of literature implicating ERK in long-term synaptic plasticity (for review, see Sweatt, 2001). The most prominent role for ERK has been in the induction of longterm potentiation (LTP) through activation of NMDARs or mGluRs (Coogan et al., 1999; Sweatt, 2001). However, our data and those of Thiels et al. (2002) implicate ERK in LTD. In particular, we propose that ERK is specifically important in mGluRand protein synthesis-dependent LTD. Very recent data indicate that ERK is an important regulator of the protein synthesisdependent phase of LTP and regulates neuronal protein synthesis in response to neuronal activity and BDNF (Kelleher et al., 2004). How can ERK signal to induce both protein synthesis-dependent LTP and LTD?

One hypothesis to consider is that ERK is a general regulator of neuronal protein synthesis in response to different extracellular stimuli, and the specificity of the response (LTP or LTD) may be determined by the pattern of synaptic activity. Alternatively, the activation of ERK may be differentially regulated by NMDARs and mGluRs via different small GTPases. Recent work suggests that Rap1 regulates a specific subcellular fraction of ERK activity in hippocampal neurons (Morozov et al., 2003). It will be very interesting to learn how ERK and protein synthesisdependent mechanisms lead to either LTP or LTD.

\section{References}

Ahn S, Ginty DD, Linden DJ (1999) A late phase of cerebellar long-term depression requires activation of CaMKIV and CREB. Neuron 23:559-568.

Angenstein F, Greenough WT, Weiler IJ (1998) Metabotropic glutamate receptor-initiated translocation of protein kinase p90rsk to polyribosomes: a possible factor regulating synaptic protein synthesis. Proc Natl Acad Sci USA 95:15078-15083.

Bolshakov VY, Carboni L, Cobb MH, Siegelbaum SA, Belardetti F (2000) Dual MAP kinase pathways mediate opposing forms of long-term plasticity at CA3-CA1 synapses. Nat Neurosci 3:1107-1112.

Coogan AN, O’Leary DM, O'Connor JJ (1999) P42/44 MAP kinase inhibitor PD98059 attenuates multiple forms of synaptic plasticity in rat dentate gyrus in vitro. J Neurophysiol 81:103-110.

Ferraguti F, Baldani-Guerra B, Corsi M, Nakanishi S, Corti C (1999) Activation of the extracellular signal-regulated kinase 2 by metabotropic glutamate receptors. Eur J Neurosci 11:2073-2082.

Fitzjohn SM, Bortolotto ZA, Palmer MJ, Doherty AJ, Ornstein PL, Schoepp DD, Kingston AE, Lodge D, Collingridge GL (1998) The potent mGlu receptor antagonist LY341495 identifies roles for both cloned and novel mGlu receptors in hippocampal synaptic plasticity. Neuropharmacology 37:1445-1458.

Fitzjohn SM, Palmer MJ, May JE, Neeson A, Morris SA, Collingridge GL (2001) A characterisation of long-term depression induced by metabotropic glutamate receptor activation in the rat hippocampus in vitro. J Physiol (Lond) 537:421-430.

Herbert TP, Kilhams GR, Batty IH, Proud CG (2000) Distinct signalling pathways mediate insulin and phorbol ester-stimulated eukaryotic initiation factor 4F assembly and protein synthesis in HEK 293 cells. J Biol Chem 275:11249-11256.
Heynen AJ, Abraham WC, Bear MF (1996) Bidirectional modification of CA1 synapses in the adult hippocampus in vivo. Nature 381:163-166.

Huber KM, Kayser MS, Bear MF (2000) Role for rapid dendritic protein synthesis in hippocampal mGluR-dependent LTD. Science 288:1254-1257.

Karachot L, Shirai Y, Vigot R, Yamamori T, Ito M (2001) Induction of longterm depression in cerebellar Purkinje cells requires a rapidly turned over protein. J Neurophysiol 86:280-289.

Karim F, Wang CC, Gereau IV RW (2001) Metabotropic glutamate receptor subtypes 1 and 5 are activators of extracellular signal-regulated kinase signaling required for inflammatory pain in mice. $\mathrm{J}$ Neurosci 21:3771-3779.

Kawasaki H, Fujii H, Gotoh Y, Morooka T, Shimohama S, Nishida E, Hirano $\mathrm{T}$ (1999) Requirement for mitogen-activated protein kinase in cerebellar long term depression. J Biol Chem 274:13498-13502.

Kelleher III RJ, Govindarajan A, Jung HY, Kang H, Tonegawa S (2004) Translational control by MAPK signaling in long-term synaptic plasticity and memory. Cell 116:467-479.

Kemp N, Bashir ZI (1999) Induction of LTD in the adult hippocampus by the synaptic activation of AMPA/kainate and metabotropic glutamate receptors. Neuropharmacology 38:495-504.

Manahan-Vaughan D (1997) Group 1 and 2 metabotropic glutamate receptors play differential roles in hippocampal long-term depression and long-term potentiation in freely moving rats. J Neurosci 17:3303-3311.

Manahan-Vaughan D, Kulla A, Frey JU (2000) Requirement of translation but not transcription for the maintenance of long-term depression in the CA1 region of freely moving rats. J Neurosci 20:8572-8576.

Merlin LR, Bergold PJ, Wong RK (1998) Requirement of protein synthesis for group I mGluR-mediated induction of epileptiform discharges. J Neurophysiol 80:989-993.

Morozov A, Muzzio IA, Bourtchouladze R, Van-Strien N, Lapidus K, Yin D, Winder DG, Adams JP, Sweatt JD, Kandel ER (2003) Rapl couples cAMP signaling to a distinct pool of p42/44MAPK regulating excitability, synaptic plasticity, learning, and memory. Neuron 39:309-325.

Moult PR, Schnabel R, Kilpatrick IC, Bashir ZI, Collingridge GL (2002) Tyrosine dephosphorylation underlies DHPG-induced LTD. Neuropharmacology 43:175-180.

Oliet SH, Malenka RC, Nicoll RA (1997) Two distinct forms of long-term depression coexist in CAl hippocampal pyramidal cells. Neuron 18:969-982.

Palmer MJ, Irving AJ, Seabrook GR, Jane DE, Collingridge GL (1997) The group I mGlu receptor agonist DHPG induces a novel form of LTD in the CA1 region of the hippocampus. Neuropharmacology 36:1517-1532.

Pearson G, Robinson F, Beers Gibson T, Xu BE, Karandikar M, Berman K, Cobb MH (2001) Mitogen-activated protein (MAP) kinase pathways: regulation and physiological functions. Endocr Rev 22:153-183.

Peavy RD, Conn PJ (1998) Phosphorylation of mitogen-activated protein kinase in cultured rat cortical glia by stimulation of metabotropic glutamate receptors. J Neurochem 71:603-612.

Peavy RD, Chang MS, Sanders-Bush E, Conn PJ (2001) Metabotropic glutamate receptor 5-induced phosphorylation of extracellular signalregulated kinase in astrocytes depends on transactivation of the epidermal growth factor receptor. J Neurosci 21:9619-9628.

Rammes G, Palmer M, Eder M, Dodt HU, Zieglgansberger W, Collingridge GL (2003) Activation of $m$ Glu receptors induces LTD without affecting postsynaptic sensitivity of CA1 neurons in rat hippocampal slices. J Physiol (Lond) 546:455-460.

Raymond CR, Thompson VL, Tate WP, Abraham WC (2000) Metabotropic glutamate receptors trigger homosynaptic protein synthesis to prolong long-term potentiation. J Neurosci 20:969-976.

Roberson ED, English JD, Adams JP, Selcher JC, Kondratick C, Sweatt JD (1999) The mitogen-activated protein kinase cascade couples PKA and $\mathrm{PKC}$ to cAMP response element binding protein phosphorylation in area CA1 of hippocampus. J Neurosci 19:4337-4348.

Rush AM, Wu J, Rowan MJ, Anwyl R (2002) Group I metabotropic glutamate receptor (mGluR)-dependent long-term depression mediated via p38 mitogen-activated protein kinase is inhibited by previous highfrequency stimulation and activation of mGluRs and protein kinase $\mathrm{C}$ in the rat dentate gyrus in vitro. J Neurosci 22:6121-6128.

Schnabel R, Kilpatrick IC, Collingridge GL (1999) An investigation into signal transduction mechanisms involved in DHPG-induced LTD in the CA1 region of the hippocampus. Neuropharmacology 38:1585-1596. 
Snyder EM, Philpot BD, Huber KM, Dong X, Fallon JR, Bear MF (2001) Internalization of ionotropic glutamate receptors in response to mGluR activation. Nat Neurosci 4:1079-1085.

Sweatt JD (2001) The neuronal MAP kinase cascade: a biochemical signal integration system subserving synaptic plasticity and memory. J Neurochem 76:1-10.

Thiels E, Barrionuevo G, Berger TW (1994) Excitatory stimulation during postsynaptic inhibition induces long-term depression in hippocampus in vivo. J Neurophysiol 72:3009-3016.

Thiels E, Kanterewicz BI, Norman ED, Trzaskos JM, Klann E (2002) Longterm depression in the adult hippocampus in vivo involves activation of extracellular signal-regulated kinase and phosphorylation of Elk-1. J Neurosci 22:2054-2062.

Wang L, Proud CG (2002) Ras/Erk signaling is essential for activation of protein synthesis by Gq protein-coupled receptor agonists in adult cardiomyocytes. Circ Res 91:821-829.

Watabe AM, Carlisle HJ, O’Dell TJ (2002) Postsynaptic induction and pre- synaptic expression of group $1 \mathrm{mGluR}$-dependent LTD in the hippocampal CA1 region. J Neurophysiol 87:1395-1403.

Xiao MY, Zhou Q, Nicoll RA (2001) Metabotropic glutamate receptor activation causes a rapid redistribution of AMPA receptors. Neuropharmacology 41:664-671.

Zakharenko SS, Zablow L, Siegelbaum SA (2002) Altered presynaptic vesicle release and cycling during mGluR-dependent LTD. Neuron 35:1099-1110.

Zhao W, Bianchi R, Wang M, Wong RK (2004) Extracellular signal-regulated kinase $1 / 2$ is required for the induction of group I metabotropic glutamate receptor-mediated epileptiform discharges. J Neurosci 24:76-84.

Zho WM, You JL, Huang CC, Hsu KS (2002) The group I metabotropic glutamate receptor agonist (S)-3,5-dihydroxyphenylglycine induces a novel form of depotentiation in the CA1 region of the hippocampus. J Neurosci 22:8838-8849.

Zhu JJ, Qin Y, Zhao M, Van Aelst L, Malinow R (2002) Ras and Rap control AMPA receptor trafficking during synaptic plasticity. Cell 110:443-455. 